\title{
Microglia Ontology and Signaling
}

\author{
Ayman EIAli ${ }^{1}$ and Serge Rivest ${ }^{2 *}$ \\ ${ }^{1}$ Neuroscience Laboratory, CHU de Québec Research Center (CHUL), Department of Psychiatry and Neuroscience, Faculty \\ of Medicine, Laval University, Quebec, CA, Canada, ${ }^{2}$ Neuroscience Laboratory, CHU de Québec Research Center (CHUL), \\ Department of Molecular Medicine, Faculty of Medicine, Laval University, Quebec, CA, Canada
}

Microglia constitute the powerhouse of the innate immune system in the brain. It is now widely accepted that they are monocytic-derived cells that infiltrate the developing brain at the early embryonic stages, and acquire a resting phenotype characterized by the presence of dense branching processes, called ramifications. Microglia use these dynamic ramifications as sentinels to sense and detect any occurring alteration in brain homeostasis. Once a danger signal is detected, such as molecular factors associated to brain damage or infection, they get activated by acquiring a less ramified phenotype, and mount adequate responses that range from phagocyting cell debris to secreting inflammatory and trophic factors. Here, we review the origin of microglia and we summarize the main molecular signals involved in controlling their function under physiological conditions. In addition, their implication in the pathogenesis of multiple sclerosis and stress is discussed.

\section{OPEN ACCESS}

Edited by:

Adelaide Fernandes, University of Lisbon, Portugal

Reviewed by:

Raman Chandrasekar, Kansas State University, USA

Noah Lucas Weisleder,

The Ohio State University, USA

${ }^{*}$ Correspondence:

Serge Rivest

serge.rivest@crchuq.ulaval.ca

Specialty section:

This article was submitted to

Molecular Medicine,

a section of the journal

Frontiers in Cell and Developmental

Biology

Received: 04 April 2016

Accepted: 15 June 2016

Published: 29 June 2016

Citation:

ElAli A and Rivest S (2016) Microglia

Ontology and Signaling.

Front. Cell Dev. Biol. 4:72.

doi: 10.3389/fcell.2016.00072
Keywords: microglia origin, brain, developmental biology, signaling pathways, innate immunity

\section{THE ORIGIN OF MICROGLIA}

The name microglia is derived from micro (i.e., small) and glia (i.e., glue). Resident microglia are mononuclear phagocytes and constitute the main resident immune cell population of the brain, representing up to $10 \%$ of the cells in the brain (Soulet and Rivest, 2008). Microglia were firstly visualized and identified in 1919 (reviewed in Tremblay et al., 2011, 2015), and despite the extensive research conducted since then, the origin of microglia is still elusive. Several different origins have been proposed for these cells. For instance, it has been proposed that microglia are derived from progenitors that originate from the neuroectoderm and/or the mesoderm, which colonize the brain from the early embryonic stage and throughout the fetal development stage (Chan et al., 2007; Soulet and Rivest, 2008). In addition, it has been proposed that microglia are derived from circulating blood monocytes, especially from the late gestational stage throughout the early post-natal stage (Chan et al., 2007). Despite these different proposed origins, a consensus view holds that microglia are derived from myeloid progenitors that infiltrate the brain during the different brain developmental stages. It is noteworthy to mention that $\sim 95 \%$ of the microglia population are generated post-natally and more precisely after the formation of the blood-brain barrier (BBB). Once again, how these cells are maintained in the adult brain during lifespan is a matter of debate. One major view suggests that microglia are maintained in the adult brain through either a self-renewal process or by the expansion of a reservoir of progenitors that have colonized the developing brain (Soulet and Rivest, 2008). Another major view suggests that microglia are maintained in the adult brain through a turnover process by the differentiation of precursors present in the blood circulation, namely monocytes, that infiltrate the adult brain (Soulet and Rivest, 2008). However, the relevance of this turnover process under physiological condition is still unclear. 
Regardless their exact origin, it is widely accepted now that once microglial progenitors have infiltrated the brain, they adopt a highly ramified morphology (Kettenmann et al., 2011). Early reports suggested that this phenotype translates a resting state of these cells. This ramified phenotype is characterized by the presence of long cellular branching processes and a small cell body. While the cellular branches are constantly moving, the cell body remains in place. Recent findings revolutionized our understating for the function of microglia by showing that these cells are never resting and are continuously patrolling the brain in quest of any alteration in cerebral homeostasis (Kettenmann et al., 2013; Figure 1). More precisely, these recent findings showed that microglia use their dynamic and motile cellular processes as sentinels to survey and scan the microenvironment within their vicinity to detect any occurring change in brain homeostasis (Kettenmann et al., 2013). Microglia rapidly get activated in the presence of a threat and they adopt a less ramified and more amoeboid phenotype with a large soma. Following activation, these cells rapidly mount appropriate responses in order to deal with the emerging threat, which could range from phagocytosis to the release of molecular mediators, including immune and non-immune factors (Kettenmann et al., 2013; Lampron et al., 2013a). The new technical advances, especially intravital two-photon imaging in live animals, shed the light on the fascinating nature of microglia and outlined a more sophisticated role fulfilled by these cells in maintaining the brain tissue integrity under both physiological and pathophysiological conditions, by detecting both non-pathological- and pathological-derived molecular cues (Davalos et al., 2005; Nimmerjahn et al., 2005). These new studies showed for instance that microglia continuously scan the microenvironment within their vicinity by accurately and significantly modulating the length and the direction of their processes without detecting significant movement of their cell bodies. Under physiological conditions, these studies revealed how microglia through their processes make what seem to be specific and repeated cell-cell contacts, namely with neurons, astrocytes, and endothelial cells (Nimmerjahn et al., 2005; Figure 1). These functions are potentiated under pathophysiological conditions, where a focal and limited laserinduced cerebral damage stimulated the extension of microglial cell processes toward the injury site in few minutes (Davalos et al., 2005). In addition, even microglia that were not in a direct contact with the damaged area detected the damage, which led to their rapid mobilization toward the injury site (Davalos et al., 2005). Taken together, these reports highlight the dynamic nature of microglia and new insights into their functions.

\section{SIGNALING IN MICROGLIA}

Microglia are highly dynamic and undergo extreme remodeling process throughout lifespan. For example, it has been suggested that the concerted movements of microglial cell processes could survey the entire brain every couple of hours (Nimmerjahn et al., 2005). Importantly, this behavior requires a tight controlled regulation of the movement of cell processes, cell motility, cell morphology, phagocytosis, immune functions, and the secretion of molecular mediators. These functions are tightly and precisely controlled by several signaling pathways (Figure 2). Here, we will briefly present major signaling pathways that play essential roles in controlling key functions of microglia.

\section{Pattern Recognition Receptor Signaling}

Being the major line of defense in the brain, microglia express several receptors involved in the control of innate immune functions, especially the pattern recognition receptors (PRRs) that regroup three major receptor families, toll-like receptors (TLRs), nucleotide-binding oligomerization domain (nod)-like receptors (NLRs), and the retinoic acid-inducible gene-1 (RIG1)like receptors (RLRs). These receptors recognize specific ligands, or "patterns," called pathogen-associated molecular patterns (PAMPs) and danger-associated molecular patterns (DAMPs). These patterns include protein molecules, such as exogenous peptidoglycans and endogenous heat shock proteins, and nonprotein molecules, such as adenosine triphosphate (ATP) and nucleic acid molecules (Kumar et al., 2011). Activation of these receptors induces specific signaling pathways that are involved in modulating microglial functions. TLR activation stimulates the recruitment of specific intracellular adaptor proteins, namely the myeloid differentiation primary response gene-88 (Myd88) that leads mainly to the induction of nuclear factor-kappa B (NF$\kappa \mathrm{B})$ signaling pathway, and toll/interleukin-1 receptor (TIR)domain-containing adapter-inducing interferon- $\beta$ (TRIF) that leads mainly to the induction of interferon regulatory factor3 (IRF3) signaling pathway. It is noteworthy to mention that among the 11 TLRs in humans and 13 in rodents, only TLR3 and TLR4 seem to signal via TRIF (Rivest, 2009; Lampron et al., 2013a). Until now, 21 NLRs have been identified, among which NLR pyrin domain containing (NLRP)1/2/3/6/10 and NOD1/2 are highly expressed in microglia (Rosenzweig et al., 2011). NLRP3 and NOD2 are the most studied receptors. NLRP3 activation mediates its oligomerization and stimulates the formation of a caspase- 1 containing inflammasome that trigger the production of the active form of interleukine$1 \beta$ (IL1 $\beta$ ), which in turn activates downstream signaling pathways (Zambetti et al., 2012). On the other hand, NOD2 activation has been shown to stimulate the recruitment of the adaptor protein receptor-interacting serine/threonine-protein kinase-2 (RICK) that leads mainly to the induction of NF- $\kappa$ B signaling pathway (Ribes et al., 2012). Finally, RLR activation stimulates the recruitment of intracellular adaptor proteins, namely mitochondrial antiviral-signaling protein (MAVS) and tumor necrosis factor (TNF) receptor associated factor (TRAF), both of which trigger NF- $\kappa$ B signaling pathway (Yoneyama and Fujita, 2010). In addition, triggering RLRs could lead to the induction of IRF3 signaling pathway (Yoneyama and Fujita, 2010). In summary, PRR signal transduction converges mainly on two major signaling pathways, namely NF-кB and IRF3.

\section{Cytokine Receptor Signaling}

Microglia express a wide range of cytokine receptors that play a crucial role in modulating microglial cell function. 


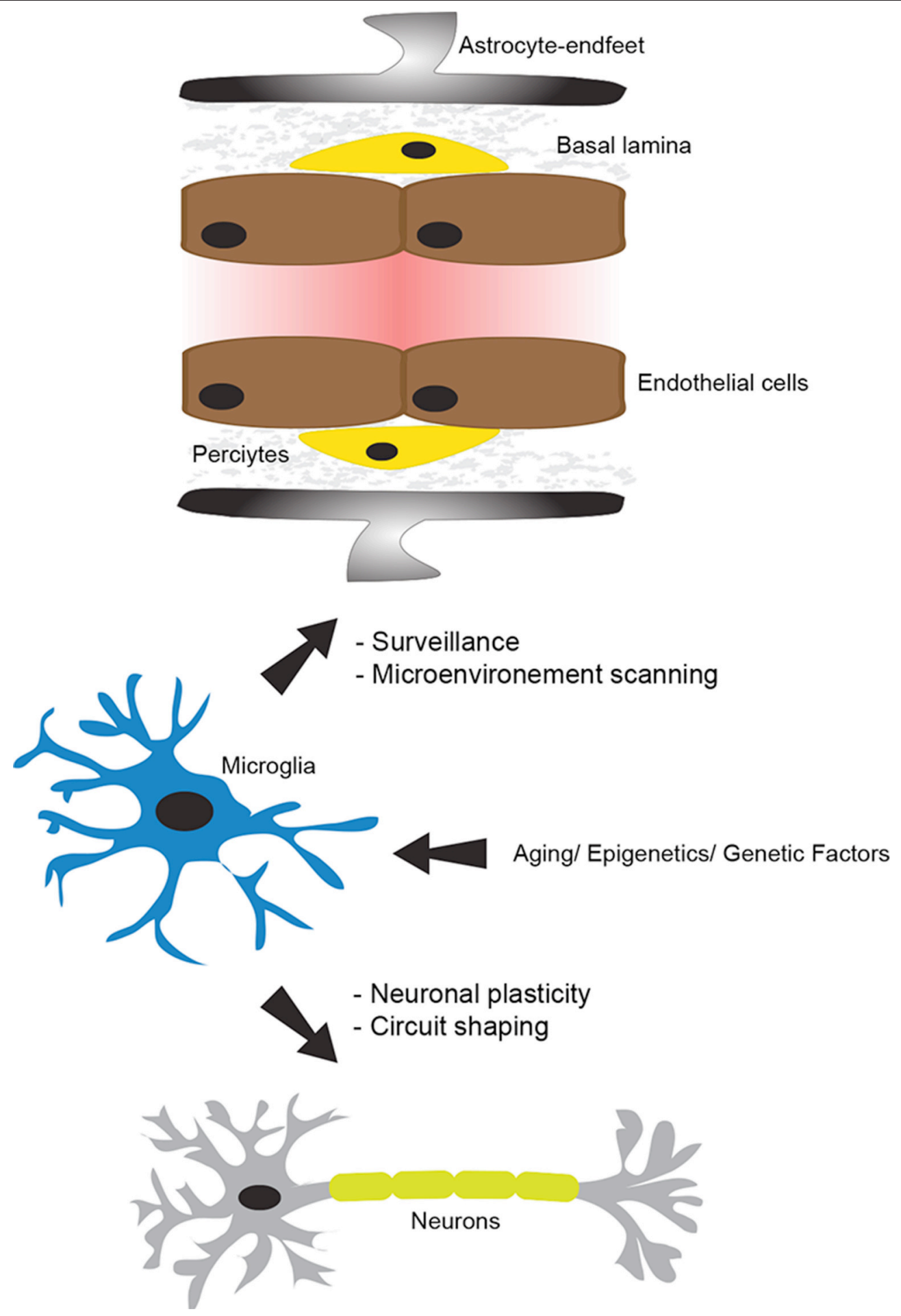

FIGURE 1 | The physiological role of microglia. The neurovascular unit (NVU), which is constituted of tightly sealed endothelial cells, basal lamina, pericytes, astrocyte-endfeet, microglia, and neurons, plays a central role in maintaining brain homeostasis and functioning. In the non-neuropathological conditions, microglia use their dynamic processes to constantly survey and screen the microenvironment within the NVU. Microglia are fully equipped to detect a wide range of signals associated to an altered brain homeostasis. In addition, they actively and dynamically communicate with neurons and play an important role in supporting their functions. Importantly, their physiological role in the intact brain can be altered by several intrinsic factors, such as aging, epigenetics, and genetics. This figure has been adapted from EIAli and Rivest (2015). 


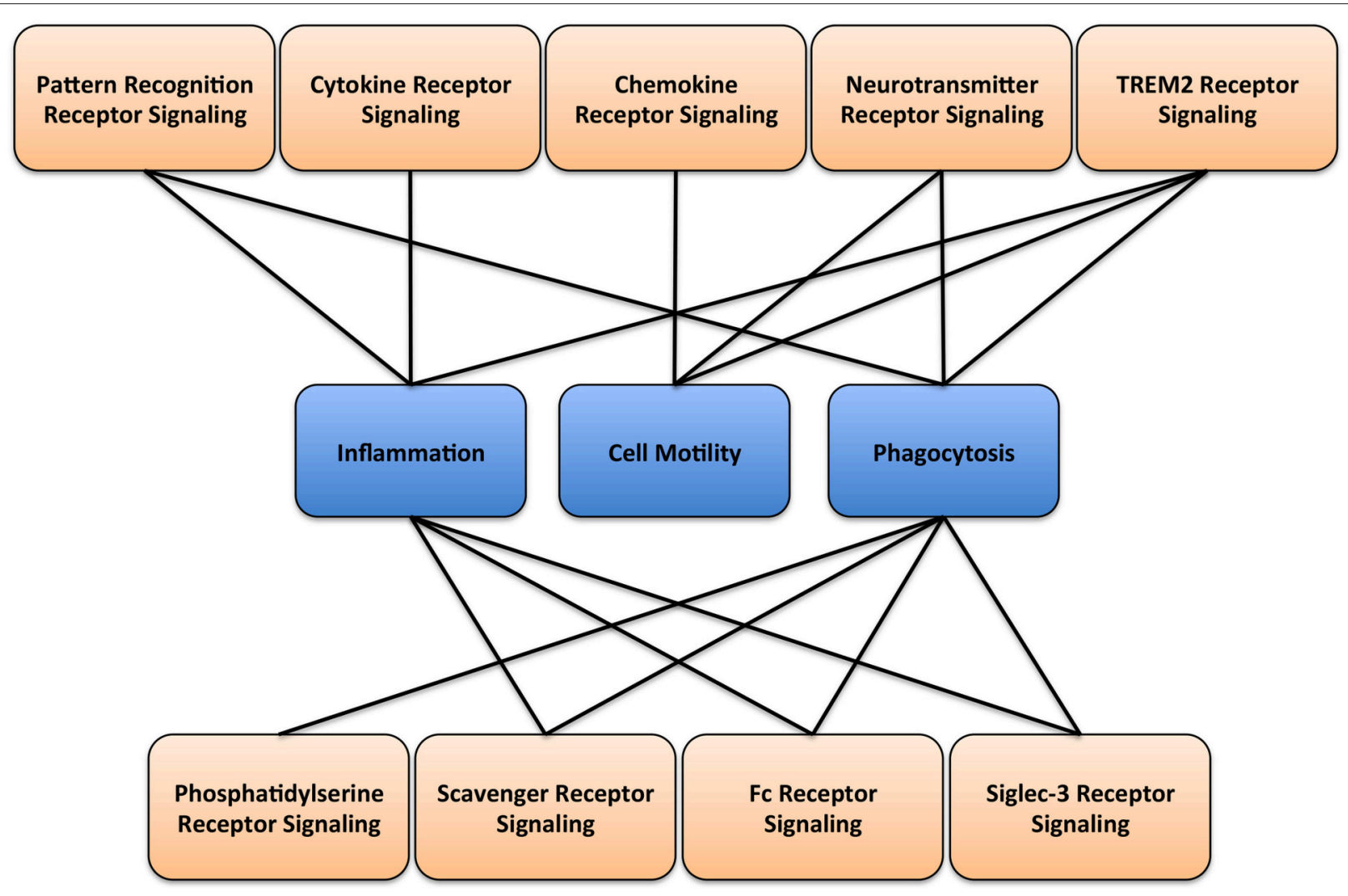

FIGURE 2 | Microglial signaling and function. A diagram illustrating the main receptor-mediated signaling associated with respective microglial cellular functions.

They also produce a large repertoire of cytokines that are essential in mediating cell functions. Among these cytokines, $\mathrm{TNF} \alpha$, transforming growth factor- $\beta$ (TGF $\beta$ ), and interleukin signaling pathways play major roles. Microglia express both TNF receptor subtypes, TNF receptor 1 (TNFR1/p55) and TNF receptor 2 (TNFR2/p75), and are, in parallel, a major source of TNF $\alpha$ in the brain (Dopp et al., 1997). It has been demonstrated that TNFR1 has a higher binding activity for soluble TNF $\alpha$ compared to TNFR2. On the other hand, TNFR2 has higher affinity to the membrane-anchored $\mathrm{TNF} \alpha$, which has been shown to play an important role in cell crosstalk (Veroni et al., 2010). Although both receptors have similar extracellular domains, their intracellular domains are structurally quite different, which translate the capacity of both receptors to trigger distinct and overlapping signaling pathways. TNFR1 and TNFR2 activation stimulates the recruitment of intracellular adaptor proteins that mediate the activation of downstream signaling pathways (MacEwan, 2002). Among these adaptor proteins, TNF receptor-associating factors (TRAFs) play an important role in orchestrating the formation of an intracellular signaling complex (MacEwan, 2002). Activation of both receptors triggers mainly the NF- $\mathrm{B}$ signaling pathway (Sriram et al., 2006). Interestingly, several reports have demonstrated that TNFR1 exacerbates the inflammation (Longhi et al., 2013), whereas TNFR2 is neuroprotective (Marchetti et al., 2004). TNFR activation increases the release of $\mathrm{TNF} \alpha$ by microglia, which creates a positive autocrine regulatory mechanism that actively participates in microglial cell activation (Nadeau and Rivest, 2000; Kuno et al., 2005).

In contrast to $\mathrm{TNF} \alpha$ that plays an important role in potentiating microglial pro-inflammatory responses, TGF $\beta$ has been shown to play a role in counter-regulating these responses (Suzumura et al., 1993). TGF $\beta$ is a multifunctional cytokine that binds TGF $\beta$ receptor type II (TGFRII) and stimulates the recruitment of TGF $\beta$ receptor type I (TGFRI). Initially, this cytokine is released as inactive complex, from which the active form is released through different processes (Feng and Derynck, 2005). Interestingly, the CD36 receptor, which is abundantly expressed on microglia (El Khoury et al., 2003), has been shown to contribute in such an activation process (Yehualaeshet et al., 1999). Upon activation, the TGFRI/RII complex receptor triggers the formation of Small and Mothers Against Decaplentaplegic-2/3/4 (SMAD-2/3/4) protein complex that translocates into the nucleus to regulate the expression of several target genes (Feng and Derynck, 2005). In parallel, TGF $\beta$ mediates its effects through another signaling pathway, independently of SMADs, which results in the activation of mitogen-activated protein kinase (MAPK) and Rho GTPases signaling pathways (Engel et al., 1999). TGF $\beta$ signaling pathway has also been shown to reduce the production of IL6, IFN $\gamma$, and several chemokines, namely monocyte chemoattractant protein1 [MCP1; i.e., chemokine ligand 2 (CCL2); Letterio and Roberts, 
1998] as well as the production of nitric oxide (NO) and the formation of reactive oxygen species (ROS; Vodovotz et al., 1993).

Microglia express several IL receptors (ILRs), namely IL1Rs [e.g., IL1 type I receptor (IL1RI), IL1 type II receptor (IL1RII), and IL1 receptor accessory protein (IL1RAcP)], IL5R, IL6R, IL8R, IL9R, IL10R, IL12R, IL13R, and IL15R. IL1 $\beta$ and IL6 play particularly important roles in the microglial cell function. IL1 $\beta$ signaling pathway potentiates microglial pro-inflammatory responses. This cytokine is essentially produced in the early stages of the innate immune response engagement, in response to TLR/Myd88/NF-кB activation (Herx et al., 2000). IL1 $\beta$ is initially produced as an inactive protein, from which the active form is generated via a proteolytic process that includes the formation of an inflammasome (John et al., 2005). IL1 $\beta$ activates a receptor complex formed by IL1RI and IL1RAP (Steinman, 2013), thus inducing NF-kB signaling pathway (Spörri et al., 2001). IL6 is considered as a pro-inflammatory cytokine that upon binding IL6R stimulates the recruitment of gp130 receptor (Erta et al., 2012). The receptor complex activates several intracellular signaling pathways, namely signal transducer and activator of transcription (STAT) pathway, MAPK pathway, and phosphatidyl inositol-3 kinase (PI3K) pathway (Erta et al., 2012). The role of IL6 in the brain is complex and not yet completely understood. Finally, IL4 and IL10 are potent anti-inflammatory molecules that have been shown to deeply affect microglial cell function (Ledeboer et al., 2000).

\section{Chemokine Receptor Signaling}

Chemokines are small chemotaxic cytokines that possess the ability to induce chemotaxis in nearby responsive cells. Chemokines are a large family of molecules that are characterized by the presence of conserved cysteine residues in their $\mathrm{N}$ terminal sequences. Based on the spacing of their first two cysteine residues, they are classified into four distinct subgroups, $\mathrm{C}$ chemokines (i.e., one $\mathrm{N}$-terminal cysteine), CC chemokines (i.e., two adjacent $\mathrm{N}$-terminal cysteines), CXC chemokines (i.e., one amino acid between the two $\mathrm{N}$-terminal cysteines), and finally CX3C chemokines (i.e., three amino acids between the two N-terminal cysteines; Fernandez and Lolis, 2002). Chemokines are produced in the brain by different populations of cells, such as neurons and microglia. All chemokines mediate their effects following their release as soluble molecules that generate a chemotactic gradient for cell mobilization and migration, except CX3C ligand 1 (CX3CL1; i.e., fractalkine) that mediates its effect either as a soluble molecule or a membrane-anchored molecule (Fernandez and Lolis, 2002). Depending on the nature of the stimuli, the chemokines are functionally divided into two groups, homeostatic, which are constitutively produced and contribute in basal cell migration, and inflammatory, which are induced once the inflammatory response is engaged (Sokol and Luster, 2015). Microglia express a wide range of chemokine receptors with different expression levels that are specie- and region-dependent, namely CCL1 receptor (CCR1), CCR2, CCR3, CCR4, CCR5, CCR6, CCR7, CXCR1, CXCR2, CXCR3, CXCR4, and CXCR5 (reviewed in Kettenmann et al., 2011). Chemokine receptors are G protein-coupled receptors (GPCRs), which upon activation modulate different downstream signaling pathways that lead to the regulation of calcium $\left(\mathrm{Ca}^{2+}\right)$ homeostasis, Rho GTPases activity, and MAPK signaling pathway. The CCL2/CCR2, CCL5 [i.e., regulated on activation, normal $\mathrm{T}$ cell expressed and secreted (RANTES)]/CCR5, and CX3CL1/CX3CR1 signaling pathways play particularly important roles in microglial cell function. Following TLR activation, CCL2 is produced by microglia, thus acting in an autocrine and paracrine manner. In parallel, the CCL2/CCR2 signaling pathway plays a central role in regulating peripheral leukocyte recruitment and infiltration into the brain during inflammatory reactions (El Khoury et al., 2007). Similar to CCL2/CCR2 signaling pathway, CCL5/CCR5 signaling pathway is regulated in an autocrine and paracrine manner. Activation of this signaling pathway has been reported to suppress the production of major pro-inflammatory cytokines, namely TNF $\alpha$, IL1 $\beta$, and IL6 (Gamo et al., 2008). On the other hand, CX3CL1 is secreted essentially by neurons and binds to its receptor CX3CR1 in microglia, thus acting as messenger that is involved neuron-microglia communication. The CX3CL1/CX3CR1 signaling pathway plays an important role in regulating microglial dynamics and migration, which is central for surveying neuronal function through lifespan (Paolicelli et al., 2014). In parallel, the CX3CL1/CX3CR1 signaling pathway has been shown to control the microglial production of several pro-inflammatory cytokines, namely TNF $\alpha$, IL $1 \beta$, and IL6 (Limatola and Ransohoff, 2014). Interestingly, inactivation of both CCL5/CCR5 and CX3CL1/CX3CR1 signaling pathways was found to impair microglial migration and communication between neurons and microglia. This may result in excessive inflammatory response and neuronal damage (Gamo et al., 2008; Cho et al., 2011).

\section{Neurotransmitter Receptor Signaling}

Microglia express a wide range of different types of neurotransmitter receptors that play central role in different cell functions, namely by mediating the interaction and crosstalk between microglia and neurons in physiological and pathological conditions. Among these neurotransmitter receptors, purinoceptors, glutamate receptors, cholinergic receptors, adrenergic receptors, and dopamine receptors have been shown to play essential roles in modulating microglial cell activity (reviewed in Kettenmann et al., 2011). The purinoceptor signaling pathways play a central role in microglial cell function due to the biological significance of their natural ligands, the nucleotides. The extracellular neuronal release of nucleotides, such as ATP, ADP, uridine triphosphate (UTP), and UDP, translates a major cell dysfunction that precedes or accompanies cell death, which is perceived by microglia as alerting signals (Illes and Alexandre Ribeiro, 2004; Burnstock and Verkhratsky, 2010). These extracellular nucleotides are recognized by several purinoceptors, namely the metabotropic P1 adenosine receptors GPCRs, ionotropic P2X purinoceptors (ligand-gated cationic channels), and metabotropic P2Y purinoceptors (GPCRs; reviewed in Kettenmann et al., 2011). These receptors have the ability to modulate microglial mobility and shape (Xiang et al., 2006; Färber et al., 2008), which may result in deep changes in membrane current and $\mathrm{Ca}^{2+}$ homeostasis (Boucsein et al., 2003; Light et al., 2006). $\mathrm{Ca}^{2+}$ homeostasis regulates several downstream signaling pathways in microglia, including those 
involved in cell motility and phagocytosis (Hoffmann et al., 2003). In addition, purinoceptors are able to modulate innate immune functions in the CNS (reviewed in Kettenmann et al., 2011).

Among the glutamate receptors expressed in microglia, the ionotropic $\alpha$-Amino-3-hydroxy-5-methyl-4-isoxazolepropionic acid (AMPA) receptor and the metabotropic glutamate receptors (mGluRs) are the best characterized. These receptors are activated by glutamate released from neurons and regulate $\mathrm{Ca}^{2+}$ homeostasis, NF- $\mathrm{KB}$ signaling pathway, and TNF $\alpha$ turnover (Noda et al., 2000; Kaushal and Schlichter, 2008). The gammaaminobutyric acid (GABA) constitutes the major inhibitory neurotransmitter in the brain (Harris and Allan, 1985). The metabotropic $G$ protein-coupled receptor $G_{A B A}$ type is expressed in a subpopulation of microglia and modulates $\mathrm{Ca}^{2+}$ homeostasis and down regulates the release of IL6 (Kuhn et al., 2004). $\alpha 7$ nicotinic ( $\alpha 7 \mathrm{nAChRs}$ ) are the best characterized acetylcholine receptors in microglia, which seem to have antiinflammatory effects (De Simone et al., 2005). Adrenergic receptors regulate $\mathrm{Ca}^{2+}$ homeostasis and reduce the release of TNF $\alpha$, IL6, and NO by microglia (Färber et al., 2005). Functional D1/2-like dopamine receptors have been identified in microglia and they seem to modulate potassium $\left(\mathrm{K}^{+}\right)$homeostasis and cytokine production (Färber et al., 2005). Recent experimental findings have provided evidence that neurotransmitter signaling pathways may result in microglial cell mobility (Fontainhas et al., 2011).

\section{TREM2 Receptor Signaling}

Insights into the functions of triggering receptor expressed on myeloid cells-2 (TREM2) receptor are recently emerging. TREM2 receptor is mainly expressed in dendritic cells (DCs), osteoclasts, and microglia (Colonna, 2003). It is a cell surface receptor that belongs to the immunoglobulin (Ig) superfamily family that is encoded by a gene cluster linked to major histocompatibility complex (MHC). TREM2 is a transmembrane receptor that lacks cytoplasmic signaling element, which is replaced by a charged domain that stimulates its association with other transmembrane adaptor proteins, namely DNAXactivation protein-12 (DAP12; Colonna, 2003). The association of both receptor triggers microglia immunoreceptor tyrosinebased activation motif (ITAM) signaling pathway that leads to cytoskeleton reorganization, chemokine production, and phagocytosis stimulation, which is accompanied by a reduction in pro-inflammatory cytokine and ROS generation (Fu et al., 2014). Interestingly, the depletion of TREM2 in mice has been shown to severely impair microglial cell response to microenvironment stimuli, morphology, and migration, thus outlining an important role of this receptor in microglial cells (Rivest, 2015; Wang et al., 2015). Activation of TREM2 signaling pathway is induced upon the biding of several charged lipid derivatives, including phospholipids (Wang et al., 2015). More precisely, TREM2 seems to act as a sensor for several anionic and Zwitter-ionic lipids that are derived from the cell membrane of neurons and glial cells, as lipid derivatives generated from some organelles such as mitochondria failed to trigger TREM2 activation (Wang et al., 2015). TREM2 is able to bind the heat shock protein-60 (Hsp60), which enhances phagocytosis by these cells (Stefano et al., 2009).

A recent genome-wide association studies (GWAS) have shown that a rare Arginine-47-Histidine $(\mathrm{R} 47 \mathrm{H})$ mutation of TREM2 is associated with a substantial increase in the risk of developing Alzheimer's disease (AD; Jonsson et al., 2013). The significance of this mutation has been recently confirmed experimentally when TREM2 depletion in 5XFAD mice significantly increased cerebral amyloid beta $(A \beta)$ load due to a dysfunctional response of microglia, which fail to cluster around $A \beta$ plaques and become apoptotic (Wang et al., 2015). Importantly, in this study the authors demonstrated that TREM2 acted as a sensor of several modified lipids known to associate with fibrillar $A \beta$ in lipid membranes and to be exposed on the surface of damaged neurons, which is in line with the implications of the R47H mutation that impairs essentially TREM2 detection of lipid ligands (Wang et al., 2015). However, the implication of the cerebral $A \beta$ reduction on cognition has not been addressed, thus the functional outcome of the here above reported observations cannot be assessed (Rivest, 2015).

\section{Phosphatidylserine Receptor Signaling}

Phosphatidylserine (PS) is a phospholipid that is normally sequestered in the inner leaflet of plasma membrane, which is exposed once cells are undergoing apoptosis (Martin et al., 1995). The recognition of PS by specialized receptors (PSRs) is crucial for an efficacious clearance of cell debris by specialized phagocytes (Ravichandran, 2011). Microglia express several specialized PSRs that directly bind PS, namely brain-specific angiogenesis inhibitor-1 (BAI1), T-cell immunoglobulin mucin receptor 1 (TIM1), and TIM4 (Ravichandran, 2011). In addition, PSRs include some receptors that indirectly bind PS by using an intermediate molecule, namely c-mer proto-oncogene tyrosine kinase (MerTK) that uses growth arrest specific gene-6 (Gas6) as a bridging molecule, and vitronectin receptors (i.e., $\alpha \mathrm{v} \beta 3$ or $\alpha v \beta 5$ integrins) that use milk fat globule-EGF factor 8 protein (MFG-E8) as a bridging molecule (Ravichandran, 2011). The direct and indirect recognition of PS by PSRs are crucial in mediating apoptotic cell phagocytosis by microglia. Importantly, the cooperation and activity coordination among these receptors seem to be central in mediating an efficacious phagocytosis (Mazaheri et al., 2014). For example, BAI1 has been reported to be in charge of controlling the formation of phagosomes around dying neurons and the transport of apoptotic cargos, while TIM4 is more involved in the downstream stabilization of phagosomes (Mazaheri et al., 2014). However, both receptors are required to mediate a successful engulfment of apoptotic neurons (Mazaheri et al., 2014). Besides being central in microglial cell phagocytosis, PSR activation is accompanied by a significant reduction in the release of several pro-inflammatory molecules, such as $\mathrm{TNF} \alpha$, IL1 $\beta$, and NO (De et al., 2002).

\section{Scavenger Receptor Signaling}

Scavenger receptors (SRs) comprise structurally diverse cell membrane receptors that have been shown to contribute to several cell functions, namely adhesion, and uptake of negatively 
charged macromolecules, and oxidized or acetylated low-density lipoprotein (LDL; Canton et al., 2013). Interestingly, several classes of SRs are expressed in microglia and they play key roles in innate immunity (Peiser et al., 2002). Among these SRs, macrophage SR class AI (SR-AI), macrophage receptor with collagenous structure (MARCO), SR-B3 (i.e., CD36), macrosialin (i.e., CD68), and recently lectin-like oxidized lowdensity lipoprotein receptor-1 (LOX1) have been reported to play particularly important roles in microglial cell function. SR$\mathrm{AI}$ is a trimer integral glycoprotein composed of a cytosolic tail, a transmembrane region, a spacer domain, $\alpha$-helical coiledcoil motif, collagen-like domain, and a cysteine-rich C-terminal domain (Matsumoto et al., 1990). SR-AI seems to bind a wide range of molecules, namely modified lipids and proteins, polyribonucleotides, polysaccharides, and anionic phospholipids (de Winther et al., 2000). SR-AI activation induces production of a several inflammatory factors, namely TNF $\alpha$, IL1 $\beta$, IL-6, and NO (Coller and Paulnock, 2001). Although MARCO is a member of the SR-A family, this receptor binds additional distinct ligands, outlining a larger role in regulating cell function (Thakur et al., 2009). Indeed, MARCO activation triggers microglial cytoskeleton reorganization, a mechanism that is highly important in the process of phagocytosis and cell mobility (Granucci et al., 2003). CD36 is a member of the SR-B family that is abundantly expressed in microglia (Coraci et al., 2002). It binds a wide range of ligands, such as native/oxidized LDL, collagen, thrombospondin, oxidized phospholipids, and longchain fatty acids (Febbraio et al., 2001). Stimulation of CD36 signaling pathway enhances microglial cell phagocytosis and production of pro-inflammatory cytokines, chemokines, and ROS (El Khoury et al., 2003). CD36 has also been shown to promote the formation of a TLR4/6 heterodimer and engagement of both MyD88 and TRIF adaptors, which ultimately affect microglia functions (Stewart et al., 2010). CD68 is a member of the SR-B family that is characterized by the presence of a mucinlike motif in the extracellular domain (Kobayashi et al., 2013). It is mainly expressed on the membrane of intracellular late endosomes under normal conditions, and its expression increases following activation by oxidized LDL (Ramprasad et al., 1996). CD68 is actively involved in microglial cell phagocytosis (Perego et al., 2011). LOX1 is found as a homodimer on cell membrane, and is the only identified member of SR-E family, which has been shown to primarily bind and process oxidized LDL (Reiss et al., 2009). Recent findings have revealed that the LOX1 structure comprises a reactive backbone that can bind to a wide range of ligands, including small molecules, such as acidic phospholipids, and whole cell structure, such as apoptotic cells and bacteria (Honjo et al., 2003). Although LOX1 was originally identified as endothelial receptor for oxidized LDL (Sawamura et al., 1997), recent reports showed that this receptor is also expressed on microglial cells (Zhang et al., 2012). LOX1 activation induces NF- $\kappa \mathrm{B}$ signaling pathway that leads to the release of several proinflammatory cytokines and ROS (Zhang et al., 2012; Li et al., 2013). Importantly LOX1 is necessary for microglia for sensing diffuse signals generated by neuronal injury, such as Hsp60 (Zhang et al., 2012). Hsp60 acts as an endogenous LOX1 ligand (Delneste et al., 2002). These data suggest that LOX1 shares some functional features with TLRs, outlining the implication of this receptor in regulating brain immune responses. However, more studies are warranted to better address this point.

\section{Fc Receptor Signaling}

Fc receptors (FcRs) belong to the immunoglobulin (Ig) superfamily that binds the constant domain $(\mathrm{Fc})$ of $\mathrm{Ig}$. They are subdivided into different subclasses based on their binding to specific isotype classes and subclasses of Ig; Fc $\alpha$ R binds IgA, Fc $\delta R$ binds $\operatorname{IgD}, F c \mu R$ binds IgM, Fc $\varepsilon R$ binds IgE, and Fc $\gamma \mathrm{R}$ binds IgG (Daëron, 1997). Interestingly, microglia express all FcR subgroups (Okun et al., 2010). The cytoplasmic tail of FcRs could contain ITAM that provides a positive signal for cell activation, and immunoreceptor tyrosinebased inhibition motif (ITIM) that provides a negative signal for cell activation. As such, the outcome of the receptor aggregation is totally dependent on the immunoreceptor tyrosine-based motif that was engaged (Daëron, 1997). Typically, FcR activation results in their aggregation on cell surface, and consequently triggering ITAM signaling pathway that leads to the sequential activation of Src and Syk tyrosine kinases (Daëron, 1997). This results in triggering several downstream signaling pathways, such as NF-kB and MAPKs (Song et al., 2004). This pathway triggers deep changes in microglial cell function and behavior, mainly by modulating the release of cytokines and by enhancing their phagocytic capacity (Okun et al., 2010). In some cases, FcR aggregation on cell surface triggers ITIM signaling pathway involving Src homology region 2 domain-containing phosphatase-1 (SHP1) and Src homology region 2 domain-containing inositol phosphatase1 (SHIP1), which is a potent inhibitory mechanism for microglia (Billadeau and Leibson, 2002). In parallel, FcRs have been shown to signal independently of their binding to Ig. For instance, it has been reported that soluble FcRs can modulate the release of some cytokines, such as TNF $\alpha$ and IL6 (Okun et al., 2010). However, more studies are warranted to better address the implication of this nonIg dependent signaling pathway in regulating microglial cell function under both physiological and pathophysiological conditions.

\section{Siglec-3 Receptor Signaling}

The sialic acid-binding immunoglobulin-type lectin-3 (Siglec3 ; i.e., CD33) is a type 1 transmembrane receptor that is essentially expressed on the surface of cells that belong to the myeloid lineage (reviewed in Crocker et al., 2007). CD33 is a member of the CD33-related Siglecs, which has two extracellular immunoglobulin domains ( $\operatorname{IgV} / \operatorname{IgC} 2)$ that recognize sialic acid residues of glycoproteins and glycolipids, and an intracellular domain that contains ITIM in humans, or ITIM-like domain in rodents (Crocker et al., 2007). ITIM and ITIM-like domains act as docking sites or SHP1 and SHP2, via which CD33 and CD33-related Siglecs execute several inhibitory functions on cell adhesion, endocytosis, and cytokine release by immune cells (Crocker et al., 2007). CD33 is expressed by microglia in both the human and rodent brains, which upon activation significantly reduces microglial cell phagocytic capacity (Griciuc 
et al., 2013). In addition, Siglec-E, a CD33-related Siglecs has been recently shown to recognize neural glycocalyx, and to inhibit the phagocytosis of neural debris by microglia in vitro (Claude et al., 2013). Taken together, these reports clearly outline the central role of CD33 and CD33-related Siglecs in acting as regulatory receptors that tightly control the immune functions of microglia under both physiological and pathophysiological conditions. However, more studies are warranted in order to fully address their role in the brain.

\section{Miscellaneous Receptor Signaling}

Microglia express several other set of receptors that contribute, to different extents, in controlling and regulating their functions. The complement receptors (CRs) play a central role in the innate immune response (Crehan et al., 2012, 2013). Macrophage colony-stimulating factor receptor (m-CSFR) stimulates the phagocytic capacity of microglia, which is a critical mechanism for the clearance of amyloid beta from the CNS (Boissonneault et al., 2009). Sigma-1 receptor (S1R) is a membrane-associated protein that binds endogenous monoamine molecules, which affect $\mathrm{Ca}^{2+}$ homeostasis and suppress several key features of microglia (Hall et al., 2009). In addition, the progesterone receptor membrane component-1 (PGRMC1) has been recently identified as the putative S2R binding site (Xu et al., 2011). Interestingly, the S2R/PGRMC1 has been shown to be activity involved in regulating microglial cell activity, which had implications on neurite outgrowth (Bali et al., 2013). Finally, the OX2 (CD200) cell membrane glycoprotein receptor (CD200R), a member of the Ig superfamily, plays a role in controlling microglial cell activity (Hoek et al., 2000).

The receptor for advanced glycation endproducts (RAGE) is a multiligand receptor that belongs to the Ig superfamily, which consists of an extracellular domain, a single transmembrane domain and a cytosolic domain (Schmidt et al., 2001). It binds to a wide range of ligands, such as advanced glycosylation endproducts (AGE), S100/calgranulin family of proteins, and high mobility group box-1 (HMGB1; Schmidt et al., 2001). RAGE is expressed in microglia and induces NF- $\kappa \mathrm{B}$ and MAPK signaling pathway, which causes the release of several pro-inflammatory cytokines, such as TNF $\alpha$ and IL1 $\beta$ (Fang et al., 2010). Interestingly, RAGE mediates some of these effects by interacting with the chemotaxic GPCRs, formyl peptide receptor-1/2 (FPR1/2; Slowik et al., 2012). LDL related receptor-1 (LRP1) is a cell membrane multiligand receptor composed of an extracellular domain, a transmembrane domain and an intracellular domain that contains two NPXY motif copies involved in signal transduction (Herz and Strickland, 2001). LRP1 is an intriguing receptor due to its diverse roles in multiple unrelated biological and cellular processes, such as endocytosis, cell-cell communication, cytoskeleton reorganization, intracellular signaling, lipid homeostasis, and clearance of apoptotic cells (Lillis et al., 2008). LRP1 has an extremely wide range of various ligands that include lipoproteins, enzymes, protein complexes, endotoxins, viral proteins, and apoptotic cells (Herz and Strickland, 2001; Gardai et al., 2005). In parallel, LRP1 has been reported to interact with several other membrane receptors, namely APP, platelet-derived growth factor receptor- $\beta$ (PDGFR $\beta$ ), and $\beta 2$ integrins, the latter been implicated in LRP1-dependent cell migration (Ranganathan et al., 2011). Microglia express a high level of LRP1, which modulates several cell functions, such as phagocytosis and migration, via the regulation of janus kinase (JAK)/signal transducer and activator of transcription-1 (STAT1) and c-jun N-terminal kinase-1/2 (JNK1/2) signaling pathways, respectively (Pocivavsek et al., 2009; Jeon et al., 2012). Moreover, LRP1 signaling pathway provides potent anti-inflammatory processes in microglia (Overton et al., 2007; Gaultier et al., 2008). Taken together, these data outline an important role of LRP1 in modulating the inflammatory response by innate immune cells (Gorovoy et al., 2010; May et al., 2013).

\section{ROLE OF MICROGLIA IN BRAIN DISORDERS}

Microglia have been shown to play important roles in brain disorders. Here, we will discuss recent reports that outlined a previously unrecognized role of these cells in different pathological conditions.

\section{Microglia in Multiple Sclerosis}

Activation of microglia by lipopolysaccharide (LP) in vivo prevents the accumulation of myelin debris and avoids premature recruitment of oligodendrocyte (OD) progenitor cells (OPCs) that are restricted to the border of demyelinated regions (Glezer et al., 2006). The TLR4 ligand can induce these effects by modulating expression of key genes involved in OPC recruitment and differentiation, and in OD-mediated remyelination. In the course of an ongoing innate immune response, cells that express an oligodendrocyte transcription factor 1 (OLIG1), OLIG2, and proteolipid protein (PLP) are normally recruited to the demyelinated sites, whereas the presence of LPS increases the expression of $P d g f r \alpha$ (platelet-derived growth factor receptor, $\alpha$ polypeptide). OLIG1, OLIG2, and Pdgfra are key genes involved in OPC mobilization and remyelination process. Accordingly, LPS-induced microglia activation renders the brain tissue more responsive to myelin repair. This is also the case in response to the TLR2 ligand zymosan, which substantially increases myelination by transplanted OPCs in the retina (Setzu et al., 2006).

These data go against the proposed unfavorable role of brain inflammation in demyelinating diseases, such as multiple sclerosis (MS). However, although a single LPS injection is probably not enough to cause neurodegeneration and demyelination, long-term exposure to PAMPs, as it occurs during severe meningitis, does have profound effects on the nervous tissues. Indeed, OD death occurs in mixed cultures of glial cells that are chronically exposed to LPS, and hypomyelination occurs in developing white matter of immature rodents following intracerebral LPS injection (Lehnardt et al., 2002). Administration of LPS can also result in severe axonal and neuronal loss following sub-threshold hypoxic-ischemic insult that normally induces no discernable neuronal injury (Lehnardt et al., 2003).

Microglia has been shown to actively contribute to brain functioning by controlling the survival of developing neurons, the maintenance of developing and mature synapses, the 
maturation of neuronal circuits, and the shaping of neuronal connectivity (Tremblay et al., 2011). Importantly, microglia have been shown to densely populate the neurogenic zones, such as the subventricular zone (SVZ; Mosher et al., 2012), where they seem to be more activated compared to non-neurogenic zones (Goings et al., 2006). Interestingly, the presence of microglia in the SVZ has been demonstrated to play an important role in promoting neurogenesis and oligodendrogenesis via the production of cytokines (Shigemoto-Mogami et al., 2014). Indeed, new reports are suggesting that these innate immune cells play a central role in myelin turnover under physiological and pathophysiological conditions by phagocyting myelin debris and by influencing oligodendrogenesis. For instance, when demyelination occurs in the adult brain, microglia adopt a phenotype associated with phagocytosis and the recruitment of OPCs (Jurevics et al., 2002; Olah et al., 2012). The CX3CL1/CX3CR1 signaling pathway plays a key role in this physiological interaction between microglia and neurons (Paolicelli et al., 2011). CX3CL1 is secreted by neurons and binds to its receptor, CX3CR1, which is exclusively expressed on microglial cells in the healthy brain (Tremblay et al., 2011). The CX3CL1/CX3CR1 axis plays a crucial role in regulating microglial behavior and function, which decisively affect brain functioning (Thériault et al., 2015).

In this regard, our group has recently demonstrated that CX3CR1 depletion severely impeded myelin removal by microglia, thus exacerbating myelin debris deposition and spreading throughout the white matter of a mouse model of progressive MS induced by cuprizone-based diet (Lampron et al., 2015). This resulted in inefficient axonal remyelination characterized by aberrant myelin patterns, which demonstrates the critical role of CX3CR1 in promoting the clearance of degenerated myelin by microglial cells (Lampron et al., 2015). The knockout of CX3CR1 blocked the clearance of myelin debris by microglia, which greatly affected the integrity of axons and myelin sheaths, preventing proper remyelination. These results highlight the crucial role played by CX3CR1 in myelin removal and show that there can be no efficient remyelination following a primary demyelinating insult if myelin clearance by microglia is impaired. We also demonstrated a marked CCR2dependent infiltration of bone marrow-derived cells (BMDCs) in demyelinating areas, but these cells do not impact demyelination and remyelination.

Myelin removal is a critical step in the remyelination process (Kotter et al., 2006). Cells of the mononuclear phagocytic system, including monocyte-derived macrophages (MDM) and microglia, are actively implicated in the clearance of myelin debris. While monocytes do not migrate into the CNS under normal conditions, we and others have shown the specific infiltration of MDMs under pathological conditions (Lampron et al., 2012, 2013b). Microglia and macrophages are regarded as detrimental in MS and experimental autoimmune encephalomyelitis (EAE), through their roles in autoimmunity such as antigen presentation and pro-inflammatory cytokine production. However, these noxious roles might mask other beneficial properties. During demyelination, microglia exert a phenotype associated with phagocytosis and the recruitment of OPC. While recent work unraveled differences between the roles played by blood-borne macrophages and microglia during autoimmune-mediated demyelination (Yamasaki et al., 2014), their respective functions in the process of primary de- and remyelination of the brain were not completely understood until recently.

Immunomodulators have been very efficient in the control of acute demyelinating events in relapsing-remitting courses of MS. However, these molecules have largely been ineffective in alleviating chronic demyelination in progressive forms of the disease, suggesting a primary neurodegenerative course (Stys et al., 2012). As autoimmunity does not seem to play a significant role in progressive forms of MS, a balance between limiting demyelination and boosting remyelination of affected sites must be reached for long-term therapeutic support of these patients (Fox et al., 2012). However, the results reported in our recent study propose important new concepts to take into consideration: there can be no efficient remyelination if microglia are unable to clear degenerate myelin from affected axons. As such, an optimal treatment strategy could consist in boosting microglial phagocytic processes while limiting inflammatory responses, combined with agents targeting OD physiology.

Activated microglia may stimulate or block oligodendrogenesis dependently on the nature of released cytokines in an animal model of MS (Butovsky et al., 2006). More precisely, high levels of IFN $\gamma$ triggered microglial cells to adopt a phenotype that impeded oligodendrogenesis, which was associated with TNF $\alpha$ production. Whereas, IL-4 reversed these effects, and the injection of IL-4-activated microglial cells into the cerebrospinal fluid of mice resulted in increased oligodendrogenesis in the spinal cord and improved clinical outcomes (Butovsky et al., 2006). These results outlined a previously unknown role of microglia in influencing endogenous oligodendrogenesis via a selective production of cytokines (Butovsky et al., 2006). It has been shown that microglia exhibit a pro-inflammatory-like phenotype (i.e., M1 phenotype) during the recruitment of OPCs, which was followed by a switch toward an anti-inflammatory-like phenotype (i.e., M2 phenotype) during the maturation of OPCs (Boven et al., 2006; Miron et al., 2013). In addition, impaired myelin removal during demyelination and myelin debris accumulation alter CNS remyelination by affecting the differentiation of OPCs (Kotter et al., 2005, 2006).

\section{Microglia in Stress}

The exposure to stress induces a profound shaping of the neuronal network and deeply affects cognitive functions (Blandino et al., 2006). Interestingly, recent reports are suggesting that stress is causatively implicated in modulating the function of microglial cells, which play important roles in shaping the neuronal network in the adult brain. One of the initial reports has shown that stress significantly increases the expression of IL1 $\beta$ by microglial cells (Blandino et al., 2006). In addition, stress has been shown to stimulate the capacity of microglia to produce CCL2 and to increase the expression of TLR2 in these cells (Shimoda et al., 2006). Interestingly, stress was reported to influence microglial cell morphology as well. For instance, stress induced a specific form of microglial remodeling, which is translated by the formation of several new branching indicating a higher ramification rate (Hinwood et al., 2013). 
Although the overwhelming experimental findings are demonstrating that stress directly influences microglial cell morphology and function (Walker et al., 2013), the underlying mechanisms are still emerging. There is a wide range of evidence demonstrating the ability of stress to significantly increase the levels of circulating corticosterone (Ulrich-Lai and Herman, 2009). Steroid hormones, namely glucocorticoids, have been shown to act as regulators of microglial inflammatory activity (Sierra et al., 2008). Recently, the CX3CL1/CX3CR1 signaling pathway has been shown to be implicated in regulating the interaction between neurons and microglial in mice exposed to stress conditions (Milior et al., 2016). Disturbing neuronmicroglia communication by deregulating CX3CL1/CX3CR1 signaling pathway prevented the effects of chronic unpredictable stress on microglial function, neuronal plasticity, and depressivelike behavior (Milior et al., 2016).

Interestingly, high level of stress exposure has been linked to the severity of autism spectrum disorder (ASD) in children (Pardo et al., 2005). In parallel, several line of evidence demonstrated the presence of a sustained chronic neuroinflammatory response associated with microglial cell activation in the brain of children with ASD (Pardo et al., 2005). Indeed, the expression levels of several pro-inflammatory cytokines, such as IL6, IFN $\gamma$, and $\mathrm{TNF} \alpha$, were significantly increased in the brains of ASD patients compared with the controls (Vargas et al., 2005; Chez et al., 2007). It is supposed that the sustained chronic activation of microglia triggers the generation of a pro-inflammatory microenvironment, which contributes to brain underconnectivity due to loss of synaptic connections and neuronal death (Rodriguez and Kern, 2011). Based on these findings, it is plausible to speculate that by reducing brain inflammation it may be possible to improve the efficacy of early behavioral and learning interventions, and consequently enhance developmental outcomes of children with ASD. As such, future studies, which aim at investigating the effects of some pharmacological approaches that reduce microglial cell activation to mitigate ASD symptoms, are warranted.

\section{CONCLUDING REMARKS}

As mentioned above, microglia play an important role in maintaining brain's integrity and plasticity in normal conditions. Under these conditions, they are highly ramified cells, which continuously scan their microenvironment in order to sense the presence of any endogenous or exogenous danger signals (e.g., damaged cells, microorganisms, etc...). Microglia rapidly respond to these danger signals by orchestrating specific responses that are totally dependent on the nature of such signals, which include the release of cytokines and chemokines, and phagocytosis, in order to clear the factors that trigger these danger cues (Soulet and Rivest, 2008). Microglia react immediately to such signals. However, "activated microglia" is an ambiguous term, as recent findings have demonstrated that these cells are always in an active state while surveying brain microenvironment. This etymology rather outlines microglial cell activity shift from surveying the microenvironment to executing specific immune tasks with diverse functional outcomes. This shift is translated by major changes in microglial cell phenotype under pathological conditions. The actual suggested dichotomy in different microglia phenotypes is mainly based on the M1/M2 activation states of macrophages. Depending on the nature of the stimuli, two functionally different and extreme phenotypes have been proposed for microglia, which are essentially based on in vitro assessments. The classically activated M1 phenotype (i.e., pro-inflammatory phenotype), is induced by LPS stimulation, and the alternatively activated M2 phenotype (anti-inflammatory phenotype), is induced by IL4/10 stimulation (Saijo and Glass, 2011). M1 microglia are characterized by the excessive release of several pro-inflammatory cytokines, such as TNF $\alpha$, IL1 $\beta$, and IL6, and have a prominent phagocytic capacity (Boche et al., 2013). The alternatively activated M2 microglia are characterized by the important release of several growth and neurotropic factors, such as TGF $\beta$, vascular endothelial growth factor (VEGF), insulin-like growth factor-1 (IGF1), brain-derived neurotrophic factor (BDNF), and nerve growth factor (NGF; Saijo and Glass, 2011; Boche et al., 2013). As such, it has been proposed that a shift toward a M1 phenotype exacerbates the inflammatory response, while a shift toward a M2 phenotype helps in tissue repair and healing (Heneka et al., 2013).

However, recent lessons from macrophages suggested that the same cell has the potential to adopt M1 or M2 phenotype based on either the nature of the stimuli and/or on the original activation status of the cell before being exposed to the stimuli (Mosser and Edwards, 2008). Based on these findings, it has been suggested that it would be more appropriate to consider the phenotype adopted by microglia to be a part of a continuously evolving spectrum of phenotypes, which is dependent on the specific spatiotemporal context under which microglia were investigated (Weitz and Town, 2012). It is noteworthy to mention that most of these studies were performed in vitro using simple stimulus, which does not translate the complexity of the microenvironment in which microglia are present in vivo (Lampron et al., 2013a). In addition, the implication of some indirect effectors in vivo, such as the production of several bioactive molecules by neighboring cells cannot be excluded. As such it is too simplistic to categorize microglial activation into two functionally distinct phenotypes, which depend on the nature of the cerebral microenvironment.

\section{AUTHOR CONTRIBUTIONS}

All authors listed, have made substantial, direct and intellectual contribution to the work, and approved it for publication.

\section{ACKNOWLEDGMENTS}

This work is supported by grants from the Canadian Institutes for Health Research (CIHR) and the Multiple Sclerosis Scientific Research Foundation of Canada. SR is supported by a Canadian Research Chair in Neuroimmunology. 


\section{REFERENCES}

Bali, N., Arimoto, J. M., Morgan, T. E., and Finch, C. E. (2013). Progesterone antagonism of neurite outgrowth depends on microglial activation via Pgrmc1/S2R. Endocrinology 154, 2468-2480. doi: 10.1210/en.2012-2109

Billadeau, D. D., and Leibson, P. J. (2002). ITAMs versus ITIMs: striking a balance during cell regulation. J. Clin. Invest. 109, 161-168. doi: 10.1172/JCI0214843

Blandino, P. Jr., Barnum, C. J., and Deak, T. (2006). The involvement of norepinephrine and microglia in hypothalamic and splenic IL-1beta responses to stress. J. Neuroimmunol. 173, 87-95. doi: 10.1016/j.jneuroim.2005.11.021

Boche, D., Perry, V. H., and Nicoll, J. A. (2013). Review: activation patterns of microglia and their identification in the human brain. Neuropathol. Appl. Neurobiol. 39, 3-18. doi: 10.1111/nan.12011

Boissonneault, V., Filali, M., Lessard, M., Relton, J., Wong, G., and Rivest, S. (2009). Powerful beneficial effects of macrophage colony-stimulating factor on betaamyloid deposition and cognitive impairment in Alzheimer's disease. Brain 132, 1078-1092. doi: 10.1093/brain/awn331

Boucsein, C., Zacharias, R., Färber, K., Pavlovic, S., Hanisch, U. K., and Kettenmann, H. (2003). Purinergic receptors on microglial cells: functional expression in acute brain slices and modulation of microglial activation in vitro. Eur. J. Neurosci. 17, 2267-2276. doi: 10.1046/j.1460-9568.2003.02663.x

Boven, L. A., Van Meurs, M., Van Zwam, M., Wierenga-Wolf, A., Hintzen, R. Q., Boot, R. G., et al. (2006). Myelin-laden macrophages are anti-inflammatory, consistent with foam cells in multiple sclerosis. Brain 129, 517-526. doi: 10.1093/brain/awh707

Burnstock, G., and Verkhratsky, A. (2010). Long-term (trophic) purinergic signalling: purinoceptors control cell proliferation, differentiation and death. Cell Death Dis. 1:e9. doi: 10.1038/cddis.2009.11

Butovsky, O., Landa, G., Kunis, G., Ziv, Y., Avidan, H., Greenberg, N., et al. (2006). Induction and blockage of oligodendrogenesis by differently activated microglia in an animal model of multiple sclerosis. J. Clin. Invest. 116, 905-915. doi: $10.1172 /$ JCI26836

Canton, J., Neculai, D., and Grinstein, S. (2013). Scavenger receptors in homeostasis and immunity. Nat. Rev. Immunol. 13, 621-634. doi: 10.1038/ nri3515

Chan, W. Y., Kohsaka, S., and Rezaie, P. (2007). The origin and cell lineage of microglia: new concepts. Brain Res. Rev. 53, 344-354. doi: 10.1016/j.brainresrev.2006.11.002

Chez, M. G., Dowling, T., Patel, P. B., Khanna, P., and Kominsky, M. (2007). Elevation of tumor necrosis factor-alpha in cerebrospinal fluid of autistic children. Pediatr. Neurol. 36, 361-365. doi: 10.1016/j.pediatrneurol.2007.01.012

Cho, S. H., Sun, B., Zhou, Y., Kauppinen, T. M., Halabisky, B., Wes, P., et al. (2011). CX3CR1 protein signaling modulates microglial activation and protects against plaque-independent cognitive deficits in a mouse model of Alzheimer disease. J. Biol. Chem. 286, 32713-32722. doi: 10.1074/jbc.M111.254268

Claude, J., Linnartz-Gerlach, B., Kudin, A. P., Kunz, W. S., and Neumann, H. (2013). Microglial CD33-related Siglec-E inhibits neurotoxicity by preventing the phagocytosis-associated oxidative burst. J. Neurosci. 33, 18270-18276. doi: 10.1523/JNEUROSCI.2211-13.2013

Coller, S. P., and Paulnock, D. M. (2001). Signaling pathways initiated in macrophages after engagement of type A scavenger receptors. J. Leukoc. Biol. $70,142-148$.

Colonna, M. (2003). TREMs in the immune system and beyond. Nat. Rev. Immunol. 3, 445-453. doi: 10.1038/nril106

Coraci, I. S., Husemann, J., Berman, J. W., Hulette, C., Dufour, J. H., Campanella, G. K., et al. (2002). CD36, a Class B scavenger receptor, is expressed on microglia in Alzheimer's disease brains and can mediate production of reactive oxygen species in response to $\beta$-amyloid fibrils. Am. J. Pathol. 160, 101-112. doi: $10.1016 /$ S0002-9440(10)64354-4

Crehan, H., Hardy, J., and Pocock, J. (2012). Microglia, Alzheimer's disease, and complement. Int. J. Alzheimers Dis. 2012:983640. doi: 10.1155/2012/983640

Crehan, H., Hardy, J., and Pocock, J. (2013). Blockage of CR1 prevents activation of rodent microglia. Neurobiol. Dis. 54, 139-149. doi: 10.1016/j.nbd.2013.02.003

Crocker, P. R., Paulson, J. C., and Varki, A. (2007). Siglecs and their roles in the immune system. Nat. Rev. Immunol. 7, 255-266. doi: 10.1038/nri2056

Daëron, M. (1997). Fc receptor biology. Annu. Rev. Immunol. 15, 203-234. doi: 10.1146/annurev.immunol.15.1.203
Davalos, D., Grutzendler, J., Yang, G., Kim, J. V., Zuo, Y., Jung, S., et al. (2005). ATP mediates rapid microglial response to local brain injury in vivo. Nat. Neurosci. 8, 752-758. doi: $10.1038 / \mathrm{nn} 1472$

De Simone, R., Ajmone-Cat, M. A., Carnevale, D., and Minghetti, L. (2005). Activation of $\alpha 7$ nicotinic acetylcholine receptor by nicotine selectively upregulates cyclooxygenase-2 and prostaglandin E2 in rat microglial cultures. J. Neuroinflammation 2:4. doi: 10.1186/1742-2094-2-4

de Winther, M. P., van Dijk, K. W., Havekes, L. M., and Hofker, M. H. (2000). Macrophage scavenger receptor class A: a multifunctional receptor in atherosclerosis. Arterioscler. Thromb. Vasc. Biol. 20, 290-297. doi: 10.1161/01.ATV.20.2.290

De, S. R., Ajmone-Cat, M. A., Nicolini, A., and Minghetti, L. (2002). Expression of phosphatidylserine receptor and down-regulation of pro-inflammatory molecule production by its natural ligand in rat microglial cultures. $J$. Neuropathol. Exp. Neurol. 61, 237-244. doi: 10.1093/jnen/61.3.237

Delneste, Y., Magistrelli, G., Gauchat, J. F., Haeuw, J. F., Aubry, J. P., Nakamura, K., et al. (2002). Involvement of LOX-1 in dendritic cell-mediated antigen crosspresentation. Immunity 17, 353-362. doi: 10.1016/S1074-7613(02)00388-6

Dopp, J. M., Mackenzie-Graham, A., Otero, G. C., and Merrill, J. E. (1997). Differential expression, cytokine modulation, and specific functions of type- 1 and type-2 tumor necrosis factor receptors in rat glia. J. Neuroimmunol. 75 , 104-112. doi: 10.1016/S0165-5728(97)00009-X

El Khoury, J. B., Moore, K. J., Means, T. K., Leung, J., Terada, K., Toft, M., et al. (2003). CD36 mediates the innate host response to beta-amyloid. J. Exp. Med. 197, 1657-1666. doi: 10.1084/jem.20021546

El Khoury, J., Toft, M., Hickman, S. E., Means, T. K., Terada, K., Geula, C., et al. (2007). Ccr2 deficiency impairs microglial accumulation and accelerates progression of Alzheimer-like disease. Nat. Med. 13, 432-438. doi: $10.1038 / \mathrm{nm} 1555$

ElAli, A., and Rivest, S. (2015). Microglia in Alzheimer's disease: a multifaceted relationship. Brain Behav. Immun. 55, 138-150. doi: 10.1016/j.bbi.2015.07.021

Engel, M. E., McDonnell, M. A., Law, B. K., and Moses, H. L. (1999). Interdependent SMAD and JNK signaling in transforming growth factor-beta-mediated transcription. J. Biol. Chem. 274, 37413-37420. doi: $10.1074 / \mathrm{jbc} .274 .52 .37413$

Erta, M., Quintana, A., and Hidalgo, J. (2012). Interleukin-6, a major cytokine in the central nervous system. Int. J. Biol. Sci. 8, 1254-1266. doi: 10.7150/ijbs.4679

Fang, F., Lue, L. F., Yan, S., Xu, H., Luddy, J. S., Chen, D., et al. (2010). RAGEdependent signaling in microglia contributes to neuroinflammation, Abeta accumulation, and impaired learning/memory in a mouse model of Alzheimer's disease. FASEB J. 24, 1043-1055. doi: 10.1096/fj.09-139634

Färber, K., Markworth, S., Pannasch, U., Nolte, C., Prinz, V., Kronenberg, G., et al. (2008). The ectonucleotidase cd39/ENTPDase1 modulates purinergicmediated microglial migration. Glia 56, 331-341. doi: 10.1002/glia.20606

Färber, K., Pannasch, U., and Kettenmann, H. (2005). Dopamine and noradrenaline control distinct functions in rodent microglial cells. Mol. Cell. Neurosci. 29, 128-138. doi: 10.1016/j.mcn.2005.01.003

Febbraio, M., Hajjar, D. P., and Silverstein, R. L. (2001). CD36: a class B scavenger receptor involved in angiogenesis, atherosclerosis, inflammation, and lipid metabolism. J. Clin. Invest. 108, 785-791. doi: 10.1172/JCI14006

Feng, X. H., and Derynck, R. (2005). Specificity and versatility in tgf-beta signaling through Smads. Annu. Rev. Cell Dev. Biol. 21, 659-693. doi: 10.1146/annurev.cellbio.21.022404.142018

Fernandez, E. J., and Lolis, E. (2002). Structure, function, and inhibition of chemokines. Annu. Rev. Pharmacol. Toxicol. 42, 469-499. doi: 10.1146/annurev.pharmtox.42.091901.115838

Fontainhas, A. M., Wang, M., Liang, K. J., Chen, S., Mettu, P., Damani, M., et al. (2011). Microglial morphology and dynamic behavior is regulated by ionotropic glutamatergic and GABAergic neurotransmission. PLoS ONE 6:e15973. doi: 10.1371/journal.pone.0015973

Fox, R. J., Thompson, A., Baker, D., Baneke, P., Brown, D., Browne, P., et al. (2012). Setting a research agenda for progressive multiple sclerosis: the international collaborative on progressive MS. Mult. Scler. 18, 1534-1540. doi: $10.1177 / 1352458512458169$

Fu, R., Shen, Q., Xu, P., Luo, J. J., and Tang, Y. (2014). Phagocytosis of microglia in the central nervous system diseases. Mol. Neurobiol. 49, 1422-1434. doi: 10.1007/s12035-013-8620-6 
Gamo, K., Kiryu-Seo, S., Konishi, H., Aoki, S., Matsushima, K., Wada, K., et al. (2008). G-protein-coupled receptor screen reveals a role for chemokine receptor CCR5 in suppressing microglial neurotoxicity. J. Neurosci. 28, 11980-11988. doi: 10.1523/JNEUROSCI.2920-08.2008

Gardai, S. J., McPhillips, K. A., Frasch, S. C., Janssen, W. J., Starefeldt, A., MurphyUllrich, J. E., et al. (2005). Cell-surface calreticulin initiates clearance of viable or apoptotic cells through trans-activation of LRP on the phagocyte. Cell 123, 321-334. doi: 10.1016/j.cell.2005.08.032

Gaultier, A., Arandjelovic, S., Niessen, S., Overton, C. D., Linton, M. F., Fazio, S., et al. (2008). Regulation of tumor necrosis factor receptor-1 and the IKK-NF-kappaB pathway by LDL receptor-related protein explains the antiinflammatory activity of this receptor. Blood 111, 5316-5325. doi: 10.1182/blood-2007-12-127613

Glezer, I., Lapointe, A., and Rivest, S. (2006). Innate immunity triggers oligodendrocyte progenitor reactivity and confines damages to brain injuries. FASEB J. 20, 750-752. doi: 10.1096/fj.05-5234fje

Goings, G. E., Kozlowski, D. A., and Szele, F. G. (2006). Differential activation of microglia in neurogenic versus non-neurogenic regions of the forebrain. Glia 54, 329-342. doi: 10.1002/glia.20381

Gorovoy, M., Gaultier, A., Campana, W. M., Firestein, G. S., and Gonias, S. L. (2010). Inflammatory mediators promote production of shed LRP1/CD91, which regulates cell signaling and cytokine expression by macrophages. J. Leukoc. Biol. 88, 769-778. doi: 10.1189/jlb.0410220

Granucci, F., Petralia, F., Urbano, M., Citterio, S., Di Tota, F., Santambrogio, L., et al. (2003). The scavenger receptor MARCO mediates cytoskeleton rearrangements in dendritic cells and microglia. Blood 102, 2940-2947. doi: 10.1182/blood-2002-12-3651

Griciuc, A., Serrano-Pozo, A., Parrado, A. R., Lesinski, A. N., Asselin, C. N., Mullin, K., et al. (2013). Alzheimer's disease risk gene cd33 inhibits microglial uptake of amyloid beta. Neuron 78, 631-643. doi: 10.1016/j.neuron.2013.04.014

Hall, A. A., Herrera, Y., Ajmo, C. T., Cuevas, J., and Pennypacker, K. R. (2009). Sigma receptors suppress multiple aspects of microglial activation. Glia 57, 744-754. doi: 10.1002/glia.20802

Harris, R. A., and Allan, A. M. (1985). Functional coupling of gammaaminobutyric acid receptors to chloride channels in brain membranes. Science 228, 1108-1110. doi: 10.1126/science.2581319

Heneka, M. T., Kummer, M. P., Stutz, A., Delekate, A., Schwartz, S., Vieira-Saecker, A., et al. (2013). NLRP3 is activated in Alzheimer's disease and contributes to pathology in APP/PS1 mice. Nature 493, 674-678. doi: 10.1038/nature11729

Herx, L. M., Rivest, S., and Yong, V. W. (2000). Central nervous system-initiated inflammation and neurotrophism in trauma: IL-1 beta is required for the production of ciliary neurotrophic factor. J. Immunol. 165, 2232-2239. doi: 10.4049/jimmunol.165.4.2232

Herz, J., and Strickland, D. K. (2001). LRP: a multifunctional scavenger and signaling receptor. J. Clin. Invest. 108, 779-784. doi: 10.1172/JCI200113992

Hinwood, M., Tynan, R. J., Charnley, J. L., Beynon, S. B., Day, T. A., and Walker, F. R. (2013). Chronic stress induced remodeling of the prefrontal cortex: structural re-organization of microglia and the inhibitory effect of minocycline. Cereb. Cortex 23, 1784-1797. doi: 10.1093/cercor/bhs151

Hoek, R. M., Ruuls, S. R., Murphy, C. A., Wright, G. J., Goddard, R., Zurawski, S. M., et al. (2000). Down-regulation of the macrophage lineage through interaction with OX2 (CD200). Science 290, 1768-1771. doi: $10.1126 /$ science. 290.5497 .1768

Hoffmann, A., Kann, O., Ohlemeyer, C., Hanisch, U. K., and Kettenmann, H. (2003). Elevation of basal intracellular calcium as a central element in the activation of brain macrophages (microglia): suppression of receptor-evoked calcium signaling and control of release function. J. Neurosci. 23, 4410-4419.

Honjo, M., Nakamura, K., Yamashiro, K., Kiryu, J., Tanihara, H., McEvoy, L. M., et al. (2003). Lectin-like oxidized LDL receptor-1 is a cell-adhesion molecule involved in endotoxin-induced inflammation. Proc. Natl. Acad. Sci. U.S.A. 100, 1274-1279. doi: 10.1073/pnas.0337528100

Illes, P., and Alexandre Ribeiro, J. (2004). Molecular physiology of P2 receptors in the central nervous system. Eur. J. Pharmacol. 483, 5-17. doi: 10.1016/j.ejphar.2003.10.030

Jeon, H., Kim, J. H., Kim, J. H., Lee, W. H., Lee, M. S., and Suk, K. (2012). Plasminogen activator inhibitor type 1 regulates microglial motility and phagocytic activity. J. Neuroinflammation 9:149. doi: 10.1186/1742-2094-9-149
John, G. R., Lee, S. C., Song, X., Rivieccio, M., and Brosnan, C. F. (2005). IL-1regulated responses in astrocytes: relevance to injury and recovery. Glia 49, 161-176. doi: 10.1002/glia.20109

Jonsson, T., Stefansson, H., Steinberg, S., Jonsdottir, I., Jonsson, P. V., Snaedal, J., et al. (2013). Variant of TREM2 associated with the risk of Alzheimer's disease. N. Engl. J. Med. 368, 107-116. doi: 10.1056/NEJMoa1211103

Jurevics, H., Largent, C., Hostettler, J., Sammond, D. W., Matsushima, G. K., Kleindienst, A., et al. (2002). Alterations in metabolism and gene expression in brain regions during cuprizone-induced demyelination and remyelination. J. Neurochem. 82, 126-136. doi: 10.1046/j.1471-4159.2002.00954.x

Kaushal, V., and Schlichter, L. C. (2008). Mechanisms of microglia-mediated neurotoxicity in a new model of the stroke penumbra. J. Neurosci. 28, 2221-2230. doi: 10.1523/JNEUROSCI.5643-07.2008

Kettenmann, H., Hanisch, U. K., Noda, M., and Verkhratsky, A. (2011). Physiology of microglia. Physiol. Rev. 91, 461-553. doi: 10.1152/physrev.00011.2010

Kettenmann, H., Kirchhoff, F., and Verkhratsky, A. (2013). Microglia: new roles for the synaptic stripper. Neuron 77, 10-18. doi: 10.1016/j.neuron.2012.12.023

Kobayashi, K., Imagama, S., Ohgomori, T., Hirano, K., Uchimura, K., Sakamoto, K., et al. (2013). Minocycline selectively inhibits M1 polarization of microglia. Cell Death Dis. 4:e525. doi: 10.1038/cddis.2013.54

Kotter, M. R., Li, W. W., Zhao, C., and Franklin, R. J. (2006). Myelin impairs CNS remyelination by inhibiting oligodendrocyte precursor cell differentiation. $J$. Neurosci. 26, 328-332. doi: 10.1523/JNEUROSCI.2615-05.2006

Kotter, M. R., Zhao, C., van Rooijen, N., and Franklin, R. J. (2005). Macrophagedepletion induced impairment of experimental CNS remyelination is associated with a reduced oligodendrocyte progenitor cell response and altered growth factor expression. Neurobiol. Dis. 18, 166-175. doi: 10.1016/j.nbd.2004.09.019

Kuhn, S. A., Van Landeghem, F. K., Zacharias, R., Färber, K., Rappert, A., Pavlovic, S., et al. (2004). Microglia express GABAB receptors to modulate interleukin release. Mol. Cell. Neurosci. 25, 312-322. doi: 10.1016/j.mcn.2003.10.023

Kumar, H., Kawai, T., and Akira, S. (2011). Pathogen recognition by the innate immune system. Int. Rev. Immunol. 30, 16-34. doi: 10.3109/08830185. 2010.529976

Kuno, R., Wang, J., Kawanokuchi, J., Takeuchi, H., Mizuno, T., and Suzumura, A. (2005). Autocrine activation of microglia by tumor necrosis factor-alpha. J. Neuroimmunol. 162, 89-96. doi: 10.1016/j.jneuroim.2005.01.015

Lampron, A., ElAli, A., and Rivest, S. (2013a). Innate Immunity in the CNS: redefining the relationship between the CNS and its environment. Neuron 78 , 214-232. doi: 10.1016/j.neuron.2013.04.005

Lampron, A., Larochelle, A., Laflamme, N., Préfontaine, P., Plante, M. M., Sánchez, M. G., et al. (2015). Inefficient clearance of myelin debris by microglia impairs remyelinating processes. J. Exp. Med. 212, 481-495. doi: 10.1084/jem.20141656

Lampron, A., Lessard, M., and Rivest, S. (2012). Effects of myeloablation, peripheral chimerism, and whole-body irradiation on the entry of bone marrow-derived cells into the brain. Cell Transplant. 21, 1149-1159. doi: $10.3727 / 096368911$ X593154

Lampron, A., Pimentel-Coelho, P. M., and Rivest, S. (2013b). Migration of bone marrow-derived cells into the central nervous system in models of neurodegeneration. J. Comp. Neurol. 521:3863-3876. doi: 10.1002/cne.23463

Ledeboer, A., Brevé, J. J., Poole, S., Tilders, F. J., and Van Dam, A. M. (2000). Interleukin-10, interleukin-4, and transforming growth factor$\beta$ differentially regulate lipopolysaccharide-induced production of proinflammatory cytokines and nitric oxide in co-cultures of rat astroglial and microglial cells. Glia 30, 134-142.

Lehnardt, S., Lachance, C., Patrizi, S., Lefebvre, S., Follett, P. L., Jensen, F. E., et al. (2002). The toll-like receptor TLR4 is necessary for lipopolysaccharide-induced oligodendrocyte injury in the CNS. J. Neurosci. 22, 2478-2486.

Lehnardt, S., Massillon, L., Follett, P., Jensen, F. E., Ratan, R., Rosenberg, P. A., et al. (2003). Activation of innate immunity in the CNS triggers neurodegeneration through a Toll-like receptor 4-dependent pathway. Proc. Natl. Acad. Sci. U.S.A. 100, 8514-8519. doi: 10.1073/pnas.1432609100

Letterio, J. J., and Roberts, A. B. (1998). Regulation of immune responses by TGF-beta. Annu. Rev. Immunol. 16, 137-161. doi: 10.1146/annurev. immunol.16.1.137

Li, S., Guo, Y., Zhu, P., and Yang, T. (2013). Role of Ox-LDL/LOX$1 / \mathrm{NF}-\kappa \mathrm{B}$ signaling pathway in regulation of atherosclerotic plaque growth 
by testosterone in male rabbits. Vascul. Pharmacol. 59, 131-137. doi: 10.1016/j.vph.2012.09.005

Light, A. R., Wu, Y., Hughen, R. W., and Guthrie, P. B. (2006). Purinergic receptors activating rapid intracellular $\mathrm{Ca}^{2+}$ increases in microglia. Neuron Glia Biol. 2:125. doi: $10.1017 /$ S1740925X05000323

Lillis, A. P., Van Duyn, L. B., Murphy-Ullrich, J. E., and Strickland, D. K. (2008). LDL receptor-related protein 1: unique tissue-specific functions revealed by selective gene knockout studies. Physiol. Rev. 88, 887-918. doi: 10.1152/physrev.00033.2007

Limatola, C., and Ransohoff, R. M. (2014). Modulating neurotoxicity through CX3CL1/CX3CR1 signaling. Front. Cell. Neurosci. 8:229. doi: $10.3389 /$ fncel.2014.00229

Longhi, L., Perego, C., Ortolano, F., Aresi, S., Fumagalli, S., Zanier, E. R., et al. (2013). Tumor necrosis factor in traumatic brain injury: effects of genetic deletion of p55 or p75 receptor. J. Cereb. Blood Flow Metab. 33, 1182-1189. doi: $10.1038 /$ jcbfm.2013.65

MacEwan, D. J. (2002). TNF receptor subtype signalling: differences and cellular consequences. Cell. Signal. 14, 477-492. doi: 10.1016/S0898-6568(01)00262-5

Marchetti, L., Klein, M., Schlett, K., Pfizenmaier, K., and Eisel, U. L. (2004). Tumor necrosis factor (TNF)-mediated neuroprotection against glutamate-induced excitotoxicity is enhanced by $\mathrm{N}$-methyl-D-aspartate receptor activation. Essential role of a TNF receptor 2-mediated phosphatidylinositol 3-kinasedependent NF-kappa B pathway. J. Biol. Chem. 279, 32869-32881. doi: 10.1074/jbc.M311766200

Martin, S. J., Reutelingsperger, C. P., McGahon, A. J., Rader, J. A., van Schie, R. C., LaFace, D. M., et al. (1995). Early redistribution of plasma membrane phosphatidylserine is a general feature of apoptosis regardless of the initiating stimulus: inhibition by overexpression of Bcl-2 and Abl. J. Exp. Med. 182, 1545-1556. doi: 10.1084/jem.182.5.1545

Matsumoto, A., Naito, M., Itakura, H., Ikemoto, S., Asaoka, H., Hayakawa, I., et al. (1990). Human macrophage scavenger receptors: primary structure, expression, and localization in atherosclerotic lesions. Proc. Natl. Acad. Sci. U.S.A. 87, 9133-9137. doi: 10.1073/pnas.87.23.9133

May, P., Bock, H. H., and Nofer, J. R. (2013). Low density receptor-related protein 1 (LRP1) promotes anti-inflammatory phenotype in murine macrophages. Cell Tissue Res. 354, 887-889. doi: 10.1007/s00441-013-1699-2

Mazaheri, F., Breus, O., Durdu, S., Haas, P., Wittbrodt, J., Gilmour, D., et al. (2014). Distinct roles for BAI1 and TIM-4 in the engulfment of dying neurons by microglia. Nat. Commun. 5:4046. doi: 10.1038/ncomms5046

Milior, G., Lecours, C., Samson, L., Bisht, K., Poggini, S., Pagani, F., et al. (2016). Fractalkine receptor deficiency impairs microglial and neuronal responsiveness to chronic stress. Brain Behav. Immun. 55, 114-125. doi: 10.1016/j.bbi.2015.07.024

Miron, V. E., Boyd, A., Zhao, J. W., Yuen, T. J., Ruckh, J. M., Shadrach, J. L., et al. (2013). M2 microglia and macrophages drive oligodendrocyte differentiation during CNS remyelination. Nat. Neurosci. 16, 1211-1218. doi: 10.1038/nn.3469

Mosher, K. I., Andres, R. H., Fukuhara, T., Bieri, G., Hasegawa-Moriyama, M., He, Y., et al. (2012). Neural progenitor cells regulate microglia functions and activity. Nat. Neurosci. 15, 1485-1487. doi: 10.1038/nn.3233

Mosser, D. M., and Edwards, J. P. (2008). Exploring the full spectrum of macrophage activation. Nat. Rev. Immunol. 8, 958-969. doi: 10.1038/nri2448

Nadeau, S., and Rivest, S. (2000). Role of microglial-derived tumor necrosis factor in mediating CD14 transcription and nuclear factor kappa B activity in the brain during endotoxemia. J. Neurosci. 20, 3456-3468.

Nimmerjahn, A., Kirchhoff, F., and Helmchen, F. (2005). Resting microglial cells are highly dynamic surveillants of brain parenchyma in vivo. Science 308, 1314-1318. doi: 10.1126/science.1110647

Noda, M., Nakanishi, H., Nabekura, J., and Akaike, N. (2000). AMPA-kainate subtypes of glutamate receptor in rat cerebral microglia. J. Neurosci. 20, 251-258.

Okun, E., Mattson, M. P., and Arumugam, T. V. (2010). Involvement of Fc receptors in disorders of the central nervous system. Neuromolecular Med. 12, 164-178. doi: 10.1007/s12017-009-8099-5

Olah, M., Amor, S., Brouwer, N., Vinet, J., Eggen, B., Biber, K., et al. (2012). Identification of a microglia phenotype supportive of remyelination. Glia 60, 306-321. doi: 10.1002/glia.21266

Overton, C. D., Yancey, P. G., Major, A. S., Linton, M. F., and Fazio, S. (2007). Deletion of macrophage LDL receptor-related protein increases atherogenesis in the mouse. Circ. Res. 100, 670-677. doi: 10.1161/01.RES.00002 60204.40510.aa

Paolicelli, R. C., Bisht, K., and Tremblay, M. Ė. (2014). Fractalkine regulation of microglial physiology and consequences on the brain and behavior. Front. Cell. Neurosci. 8:129. doi: 10.3389/fncel.2014.00129

Paolicelli, R. C., Bolasco, G., Pagani, F., Maggi, L., Scianni, M., Panzanelli, P., et al. (2011). Synaptic pruning by microglia is necessary for normal brain development. Science 333, 1456-1458. doi: 10.1126/science.1202529

Pardo, C. A., Vargas, D. L., and Zimmerman, A. W. (2005). Immunity, neuroglia and neuroinflammation in autism. Int. Rev. Psychiatry 17, 485-495. doi: $10.1080 / 02646830500381930$

Peiser, L., Mukhopadhyay, S., and Gordon, S. (2002). Scavenger receptors in innate immunity. Curr. Opin. Immunol. 14, 123-128. doi: 10.1016/S09527915(01)00307-7

Perego, C., Fumagalli, S., and De Simoni, M. G. (2011). Temporal pattern of expression and colocalization of microglia/macrophage phenotype markers following brain ischemic injury in mice. J. Neuroinflammation 8:174. doi: 10.1186/1742-2094-8-174

Pocivavsek, A., Mikhailenko, I., Strickland, D. K., and Rebeck, G. W. (2009). Microglial low-density lipoprotein receptor-related protein 1 modulates c-Jun N-terminal kinase activation. J. Neuroimmunol. 214, 25-32. doi: 10.1016/j.jneuroim.2009.06.010

Ramprasad, M. P., Terpstra, V., Kondratenko, N., Quehenberger, O., and Steinberg, D. (1996). Cell surface expression of mouse macrosialin and human CD68 and their role as macrophage receptors for oxidized low density lipoprotein. Proc. Natl. Acad. Sci. U.S.A. 93, 14833-14838. doi: 10.1073/pnas.93.25.14833

Ranganathan, S., Cao, C., Catania, J., Migliorini, M., Zhang, L., and Strickland, D. K. (2011). Molecular basis for the interaction of low density lipoprotein receptor-related protein 1 (LRP1) with integrin alphaMbeta2: identification of binding sites within alphaMbeta2 for LRP1. J. Biol. Chem. 286, 30535-30541. doi: $10.1074 /$ jbc.M111.265413

Ravichandran, K. S. (2011). Beginnings of a good apoptotic meal: the find-me and eat-me signaling pathways. Immunity 35, 445-455. doi: 10.1016/j.immuni.2011.09.004

Reiss, A. B., Anwar, K., and Wirkowski, P. (2009). Lectin-like oxidized low density lipoprotein receptor 1 (LOX-1) in atherogenesis: a brief review. Curr. Med. Chem. 16, 2641-2652. doi: 10.2174/092986709788681994

Ribes, S., Adam, N., Schütze, S., Regen, T., Redlich, S., Janova, H., et al. (2012). The nucleotide-binding oligomerization domain-containing-2 ligand muramyl dipeptide enhances phagocytosis and intracellular killing of Escherichia coli K1 by Toll-like receptor agonists in microglial cells. J. Neuroimmunol. 252, 16-23. doi: 10.1016/j.jneuroim.2012.07.012

Rivest, S. (2009). Regulation of innate immune responses in the brain. Nat. Rev. Immunol. 9, 429-439. doi: 10.1038/nri2565

Rivest, S. (2015). TREM2 enables amyloid $\beta$ clearance by microglia. Cell Res. 25, 535-536. doi: 10.1038/cr.2015.37

Rodriguez, J. I., and Kern, J. K. (2011). Evidence of microglial activation in autism and its possible role in brain underconnectivity. Neuron Glia Biol. 7, 205-213. doi: 10.1017/S1740925X12000142

Rosenzweig, H. L., Planck, S. R., and Rosenbaum, J. T. (2011). NLRs in immune privileged sites. Curr. Opin. Pharmacol. 11, 423-428. doi: 10.1016/j.coph. 2011.07.002

Saijo, K., and Glass, C. K. (2011). Microglial cell origin and phenotypes in health and disease. Nat. Rev. Immunol. 11, 775-787. doi: 10.1038/nri3086

Sawamura, T., Kume, N., Aoyama, T., Moriwaki, H., Hoshikawa, H., Aiba, Y., et al. (1997). An endothelial receptor for oxidized low-density lipoprotein. Nature 386, 73-77. doi: 10.1038/386073a0

Schmidt, A. M., Yan, S. D., Yan, S. F., and Stern, D. M. (2001). The multiligand receptor RAGE as a progression factor amplifying immune and inflammatory responses. J. Clin. Invest. 108, 949-955. doi: 10.1172/JCI200114002

Setzu, A., Lathia, J. D., Zhao, C., Wells, K., Rao, M. S., Ffrench-Constant, C., et al. (2006). Inflammation stimulates myelination by transplanted oligodendrocyte precursor cells. Glia 54, 297-303. doi: 10.1002/glia.20371

Shigemoto-Mogami, Y., Hoshikawa, K., Goldman, J. E., Sekino, Y., and Sato, K. (2014). Microglia enhance neurogenesis and oligodendrogenesis in the early postnatal subventricular zone. J. Neurosci. 34, 2231-2243. doi: 10.1523/JNEUROSCI.1619-13.2014 
Shimoda, M., Jones, V. C., Kobayashi, M., and Suzuki, F. (2006). Microglial cells from psychologically stressed mice as an accelerator of cerebral cryptococcosis. Immunol. Cell Biol. 84, 551-556. doi: 10.1111/j.1440-1711.2006. 01466.x

Sierra, A., Gottfried-Blackmore, A., Milner, T. A., McEwen, B. S., and Bulloch, K. (2008). Steroid hormone receptor expression and function in microglia. Glia 56, 659-674. doi: 10.1002/glia.20644

Slowik, A., Merres, J., Elfgen, A., Jansen, S., Mohr, F., Wruck, C. J., et al. (2012). Involvement of formyl peptide receptors in receptor for advanced glycation end products (RAGE)-and amyloid beta 1-42-induced signal transduction in glial cells. Mol. Neurodegener. 7:55. doi: 10.1186/1750-13 26-7-55

Sokol, C. L., and Luster, A. D. (2015). The chemokine system in innate immunity. Cold Spring Harb. Perspect. Biol. 7:a016303. doi: 10.1101/cshperspect.a016303

Song, X., Tanaka, S., Cox, D., and Lee, S. C. (2004). Fcgamma receptor signaling in primary human microglia: differential roles of PI-3K and Ras/ERK MAPK pathways in phagocytosis and chemokine induction. J. Leukoc. Biol. 75, 1147-1155. doi: 10.1189/jlb.0403128

Soulet, D., and Rivest, S. (2008). Microglia. Curr. Biol. 18, R506-R508. doi: 10.1016/j.cub.2008.04.047

Spörri, B., Bickel, M., Dobbelaere, D., Machado, J., and Lottaz, D. (2001). Soluble interleukin-1 receptor - Reverse signaling in innate immunoregulation. Cytokine Growth Factor Rev. 12, 27-32. doi: 10.1016/S1359-6101(00)00020-4

Sriram, K., Miller, D. B., and O'Callaghan, J. P. (2006). Minocycline attenuates microglial activation but fails to mitigate striatal dopaminergic neurotoxicity: role of tumor necrosis factor-alpha. J. Neurochem. 96, 706-718. doi: 10.1111/j.1471-4159.2005.03566.x

Stefano, L., Racchetti, G., Bianco, F., Passini, N., Gupta, R. S., Bordignon, P. P., et al. (2009). The surface-exposed chaperone, Hsp60, is an agonist of the microglial TREM2 receptor. J. Neurochem. 110, 284-294. doi: 10.1111/j.14714159.2009.06130.x

Steinman, L. (2013). Inflammatory cytokines at the summits of pathological signal cascades in brain diseases. Sci Signal 6:pe3. doi: 10.1126/scisignal.2003898

Stewart, C. R., Stuart, L. M., Wilkinson, K., van Gils, J. M., Deng, J., Halle, A., et al. (2010). CD36 ligands promote sterile inflammation through assembly of a Toll-like receptor 4 and 6 heterodimer. Nat. Immunol. 11, 155-161. doi: 10.1038/ni.1836

Stys, P. K., Zamponi, G. W., van Minnen, J., and Geurts, J. J. G. (2012). Will the real multiple sclerosis please stand up? Nat. Rev. Neurosci. 13, 507-514. doi: $10.1038 / \mathrm{nrn} 3275$

Suzumura, A., Sawada, M., Yamamoto, H., and Marunouchi, T. (1993). Transforming growth factor-beta suppresses activation and proliferation of microglia in vitro. J. Immunol. 151, 2150-2158.

Thakur, S. A., Hamilton, R., Pikkarainen, T., and Holian, A. (2009). Differential binding of inorganic particles to MARCO. Toxicol. Sci. 107, 238-246. doi: $10.1093 /$ toxsci/kfn210

Thériault, P., ElAli, A., and Rivest, S. (2015). The dynamics of monocytes and microglia in Alzheimer's disease. Alzheimers Res. Ther. 7:41. doi: 10.1186/s13195-015-0125-2

Tremblay, M. Ė., Lecours, C., Samson, L., Sánchez-Zafra, V., and Sierra, A. (2015). From the Cajal alumni Achúcarro and Río-Hortega to the rediscovery of never-resting microglia. Front. Neuroanat. 9:45. doi: 10.3389/fnana.2015.00045

Tremblay, M. E., Stevens, B., Sierra, A., Wake, H., Bessis, A., and Nimmerjahn, A. (2011). The role of microglia in the healthy brain. J. Neurosci. 31, 16064-16069. doi: 10.1523/JNEUROSCI.4158-11.2011
Ulrich-Lai, Y. M., and Herman, J. P. (2009). Neural regulation of endocrine and autonomic stress responses. Nat. Rev. Neurosci. 10, 397-409. doi $10.1038 / \mathrm{nrn} 2647$

Vargas, D. L., Nascimbene, C., Krishnan, C., Zimmerman, A. W., and Pardo, C. A. (2005). Neuroglial activation and neuroinflammation in the brain of patients with autism. Ann. Neurol. 57, 67-81. doi: 10.1002/ana.20315

Veroni, C., Gabriele, L., Canini, I., Castiello, L., Coccia, E., Remoli, M. E., et al. (2010). Activation of TNF receptor 2 in microglia promotes induction of anti-inflammatory pathways. Mol. Cell. Neurosci. 45, 234-244. doi: 10.1016/j.mcn.2010.06.014

Vodovotz, Y., Bogdan, C., Paik, J., Xie, Q. W., and Nathan, C. (1993). Mechanisms of suppression of macrophage nitric oxide release by transforming growth factor beta. J. Exp. Med. 178, 605-613. doi: 10.1084/jem.178.2.605

Walker, F. R., Nilsson, M., and Jones, K. (2013). Acute and chronic stressinduced disturbances of microglial plasticity, phenotype and function. Curr. Drug Targets 14, 1262-1276. doi: 10.2174/13894501113149990208

Wang, Y., Cella, M., Mallinson, K., Ulrich, J. D., Young, K. L., Robinette, M. L., et al. (2015). TREM2 lipid sensing sustains the microglial response in an Alzheimer's disease model. Cell 160, 1061-1071. doi: 10.1016/j.cell.2015.01.049

Weitz, T. M., and Town, T. (2012). Microglia in alzheimer's disease: it's all about context. Int. J. Alzheimers Dis. 2012:314185. doi: 10.1155/2012/314185

Xiang, Z., Chen, M., Ping, J., Dunn, P., Lv, J., Jiao, B., et al. (2006). Microglial morphology and its transformation after challenge by extracellular ATP in vitro. J. Neurosci. Res. 83, 91-101. doi: 10.1002/jnr.20709

Xu, J., Zeng, C., Chu, W., Pan, F., Rothfuss, J. M., Zhang, F., et al. (2011). Identification of the PGRMC1 protein complex as the putative sigma-2 receptor binding site. Nat. Commun. 2:380. doi: 10.1038/ncomms1386

Yamasaki, R., Lu, H., Butovsky, O., Ohno, N., Rietsch, A. M., Cialic, R., et al. (2014). Differential roles of microglia and monocytes in the inflamed central nervous system. J. Exp. Med. 211, 1533-1549. doi: 10.1084/jem.20132477

Yehualaeshet, T., O’Connor, R., Green-Johnson, J., Mai, S., Silverstein, R., MurphyUllrich, J. E., et al. (1999). Activation of rat alveolar macrophage-derived latent transforming growth factor beta-1 by plasmin requires interaction with thrombospondin-1 and its cell surface receptor, CD36. Am. J. Pathol. 155, 841-851. doi: 10.1016/S0002-9440(10)65183-8

Yoneyama, M., and Fujita, T. (2010). Recognition of viral nucleic acids in innate immunity. Rev. Med. Virol. 20, 4-22. doi: 10.1002/rmv.633

Zambetti, L. P., Laudisi, F., Licandro, G., Ricciardi-Castagnoli, P., and Mortellaro, A. (2012). The rhapsody of NLRPs: master players of inflammation... and a lot more. Immunol. Res. 53, 78-90. doi: 10.1007/s12026-012-8272-z

Zhang, D., Sun, L., Zhu, H., Wang, L., Wu, W., Xie, J., et al. (2012). Microglial LOX-1 reacts with extracellular HSP60 to bridge neuroinflammation and neurotoxicity. Neurochem. Int. 61, 1021-1035. doi: 10.1016/j.neuint.2012.07.019

Conflict of Interest Statement: The authors declare that the research was conducted in the absence of any commercial or financial relationships that could be construed as a potential conflict of interest.

Copyright (c) 2016 ElAli and Rivest. This is an open-access article distributed under the terms of the Creative Commons Attribution License (CC BY). The use, distribution or reproduction in other forums is permitted, provided the original author(s) or licensor are credited and that the original publication in this journal is cited, in accordance with accepted academic practice. No use, distribution or reproduction is permitted which does not comply with these terms. 